\title{
Communication by Plant Growth Regulators in Roots and Shoots of Horticultural Crops
}

\author{
Anish Malladi and Jacqueline K. Burns ${ }^{1}$ \\ University of Florida, IFAS, Horticultural Sciences Department, Citrus Research and Education Center, \\ 700 Experiment Station Road, Lake Alfred, FL 33850
}

Additional index words. apical dominance, epinasty, photoperiod, root anaerobiosis, soil moisture status, stomatal conductance, tuberization

\begin{abstract}
Plant growth regulators (PGRs) play important roles in the way plants grow and develop. Myriad processes important to horticultural crops are regulated by PGRs. Changes in the presence, balance, and distribution of PGRs communicate developmental, stress-related, or environmental cues that alter growth. Short-distance communication involves changes in biosynthesis or metabolic conversion, whereas longer-distance communication may also require export and translocation of PGRs, their precursors or metabolites. Examples are presented that demonstrate PGR communication between roots and shoots in horticultural commodities. For example, increased duration and intensity of flooding stress can result in synthesis of 1-aminocyclopropane-1-carboxylic acid (ACC), precursor of the PGR ethylene, in roots. ACC transported to the shoot through the transpiration stream is converted to ethylene and causes leaf epinasty. Roots sense the onset of water stress and can communicate the need to close leaf stomata by altering abscisic acid (ABA) levels in the shoot. Daylength and temperature regulate synthesis and transport of gibberellins, which promote stem elongation and stolon formation and inhibit tuberization in potato. Outgrowth of axillary buds following the decapitation of the apical meristem is dependent on synthesis and transport of cytokinin from root to the axillary buds as well as the balance of indole-3-acetic acid (IAA) cytokinin, and additional messengers. Current research in the field of long-distance communication within plants is uncovering novel messengers and altering our view of the central roles for PGRs in such signaling.
\end{abstract}

Long-distance communication between roots and shoots is a common feature in plants. Alteration of root conditions by factors such as drought or flooding leads to physiological responses in the shoot that occur before changes in shoot water status are apparent and occur even when shoot water status is maintained (Passioura, 1988; Sharp and Le Noble, 2002). This suggests the transmission of a chemical signal from the roots that alters shoot physiology. Similarly, shoot nitrogen status generates a shootderived signal that alters root physiology, leading to activation of nitrate uptake (Forde, 2002). Dodd (2005) suggested two criteria for defining a root-derived shoot signal that may be valid for signal-based communication over long distances in plants: 1) directional movement of the signal and 2) physiological effect of the signal on an organ (target) that is distant from the signal source. Signals that communicate information over long distances may be generated by developmental, stress-related, or environmental cues and result in positive or negative effects on the source or target tissues. An understanding of long-distance communication is essential to predict the effect of environmental and developmental cues on plant response and to design practices to improve plant performance.

Studies examining the nature of longdistance communication have shown that the common phytohormones, referred to within this article as plant growth regulators (PGRs), participate in such signaling. PGRs can be thought of as components of large signaling networks that communicate information from one part of a plant to another. By way of four examples including the communication of 1) root anaerobiosis - epinasty, 2) soil moisture status - stomatal conductance $\left.\left(g_{\mathrm{S}}\right), 3\right)$ changes in photoperiod-tuberization, and 4) apical dominance - axillary bud outgrowth, this article describes some of the roles of PGRs in communication between roots and shoots in horticultural crops. These four examples present existing views and discuss emerging concepts of root-shoot communication that demand reevaluation of the role of PGRs in long-distance signaling.

\section{COMMUNICATING ROOT ANAEROBIOSIS_EPINASTY}

Epinasty is characterized by downward curvature of leaves caused by differential cell expansion on the adaxial surface of the petiole. This movement reduces foliar absorption of light, retards transpirational water loss, and reduces drought-induced wilting (Abeles et al., 1992). Epinastic movement of petioles is caused by ethyleneinduced cell expansion of adaxial petiolar cells rather than their differential growth resulting from a local auxin gradient (Ursin and Bradford, 1989).

Tomato is particularly sensitive to waterlogging and demonstrates epinasty rapidly after the root system is flooded or deprived of oxygen (Jackson and Campbell, 1976). Leaf wilting and epinasty appear within hours of flooding, and reduction of shoot elongation, adventitious root formation, and chlorosis of leaves occur after several days (Jackson, 1956). Furkova (1944) first suggested that shoot symptoms associated with excessive watering were associated with the PGR ethylene. Subsequent work verified that increased ethylene was produced in leaves of waterlogged plants (Jackson and Campbell, 1976; Kawase, 1974) but not in roots (Bradford and Dilley, 1978). A burst of ethylene production in leaves often accompanies the transfer of waterlogged roots to aerobic environment (Jackson et al., 1978). These results suggested that a "signal" was formed in roots (source organ) of waterlogged plants and transferred to leaves (target organ) where ethylene was produced and epinasty developed. Such a signal conforms to a typical root-derived positive signal (Dodd, 2005).

Transfer of the "chemical signal" was shown to occur through the xylem (Jackson et al., 1978). Bradford and Yang (1980) demonstrated the xylem-translocated "signal" communicating root anaerobiosis to the shoot was 1-aminocyclopropane-1-carboxylic acid (ACC), the precursor to ethylene. Under anaerobic stress, ACC production is accelerated in roots as a result of increased gene transcription and enzymatic activity of ACC synthase (Olson et al., 1995). Because conversion of ACC to ethylene is an oxidation reaction catalyzed by ACC oxidase, ACC formed in roots cannot be converted to ethylene in the absence of oxygen (Wang et al., 2002). ACC oxidase activity may be expected to be completely inhibited under waterlogged conditions where oxygen levels are below 1\% (Jackson et al., 1978; Vriezen et al., 1999). Accumulated ACC is exported to the xylem, where it travels to the shoot and leaves. Once in leaves and in the presence of oxygen, ACC is converted to ethylene by ACC oxidase and epinasty results (Fig. 1).

Additional PGRs or signals may participate in facilitating the epinastic response in tomato. Cytokinin (Neuman et al., 1990) and ABA levels (Else et al., 1995) drop sharply in response to flooding, and epinasty can be partially rescued by external application of cytokinins to the shoot (Jackson, 2002). Such reductions in the levels of additional PGRs may increase ethylene sensitivity and accentuate the epinastic response.

\section{COMMUNICATING SOIL MOISTURE STATUS-STOMATAL CONDUCTANCE}

Early changes in $g_{\mathrm{S}}$ that occur as soil water is depleted are not associated with 

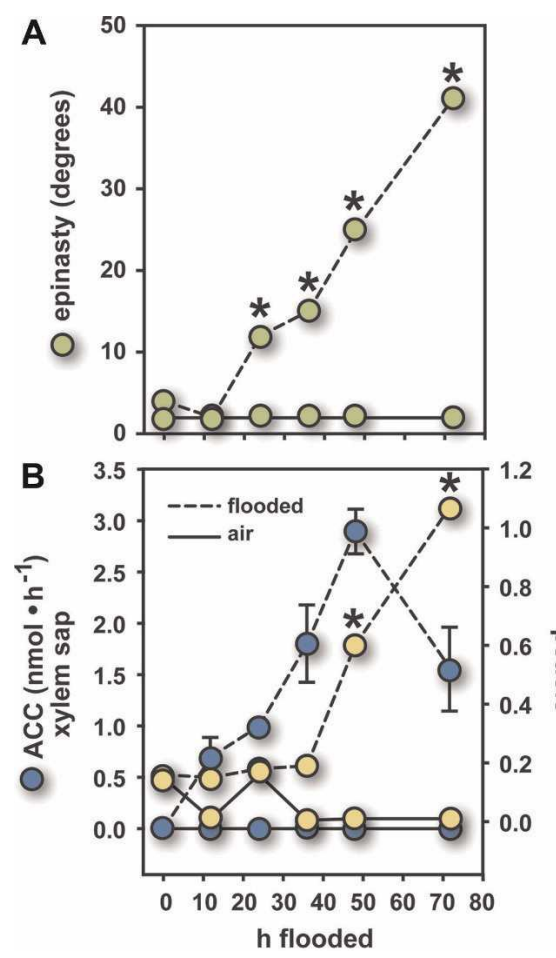

Fig. 1. Change in leaf epinasty (A), xylem 1-aminocyclopropane-1-carboxylic acid (ACC) content and ethylene evolution (B) in tomato when subjected to increased flooding duration (data from Bradford and Yang, 1980). (C) Diagram of a stylized tomato plant before (left panel) and after (right panel) prolonged flooding stress. Red arrowheads indicate acropetal movement of ACC from the site of synthesis in the roots to leaves where conversion to ethylene occurs in the presence of oxygen and epinasty results. *Statistical significance when compared with the control.

alteration in leaf water status (Bates and Hall, 1981). Rather, as demonstrated in plants such as grape (Stoll et al., 2000), English pea (Zhang and Davies, 1987), and apple (Gowing et al., 1990), change in $g_{S}$ precedes leaf wilting. Rapid reduction in $g_{\mathrm{S}}$ may prevent dehydration of leaves, whereas subsequent reduction in leaf expansion further reduces leaf area and transpirational water loss. These adjustments aid in acclimating the plant to prolonged periods of water stress.

Loveys (1984) was one of the first to suggest that a xylem-located "signal," identified as ABA, caused changes in $g_{\mathrm{S}}$ in plants under drought stress. Xylem-translocated ABA was closely correlated with stomatal closure in many plant systems (Tardieu et al., 1996) and a major point of origin of xylem ABA was thought to be droughted roots (Davies and Zhang, 1991). Decreased soil water content may decrease root water potential, increase synthesis of ABA in affected root tips, and increase $\mathrm{ABA}$ transport to leaves through the transpiration stream (Fig. 2). Initial limitations on soil moisture primarily affect shallow roots located on the soil surface, whereas water uptake from roots located in deeper, moist soil provides water for transpirational flow and movement of ABA to leaves (Zhang and Davies, 1989). Alkaline xylem $\mathrm{pH}$, characteristic of droughtstressed plants, retards ABA catabolism and its compartmentation into inactive symplastic storage in leaves, thereby increasing ABA flow to guard cells (Sauter et al., 2001;
Wilkinson and Davies, 2002). Furthermore, alkaline xylem $\mathrm{pH}$ can cause release of bound ABA in the leaf apoplast (Sobeih et al., 2004). At the guard cell, ABA increases cytosolic $\mathrm{Ca}^{2+}$ and promotes the efflux of $\mathrm{K}^{+}$and $\mathrm{Cl}^{-}$. The resulting net loss of salt ions from guard cells reduces their turgor and causes stomatal closure (Blatt and Grabov, 1997). Under prolonged drought stress, ABA synthesis may be directly induced in the leaf, thereby overwhelming the storage capacity of ABA in the symplast. A low basal level of ABA arriving from roots through the transpiration stream may then be sufficient to maintain stomatal closure, even when plants return to well-watered conditions (Trejo et al., 1995).

Recent studies in tomato and other crops suggest the possibility of alternative signals involved in root-based communication of drought stress. Holbrook et al. (2002) used two tomato mutants deficient in ABA synthesis, flacca and sitiens, to investigate the role of root-derived ABA in controlling $g_{\mathrm{S}}$. Stomatal closure in wild-type shoots grafted on ABA-deficient mutant roots occurred normally in response to soil-drying, suggesting that $\mathrm{ABA}$ synthesis in roots may not be essential for this response. Additional experiments using split-roots (partial drying) and grafting coupled with maintenance of turgor pressure (pressure chamber) indicated the presence of a root signal that was independent of the root genotype. Similar results were obtained by other authors who used sunflower mutants deficient in $\mathrm{ABA}$ (Fambrini et al., 1995) and partial root drying of tomato (Sobeih et al., 2004). These studies suggest the presence of an alternative root-based chemical signal capable of altering leaf ABA concentration and availability, facilitating stomatal responses. The nature of this signal remains unclear, although it has been speculated to be an ABA precursor (Holbrook et al., 2002). These studies lead to the notion that ABA itself may not be exclusively involved in communicating soil moisture status from roots to shoots.

\section{COMMUNICATING CHANGES IN PHOTOPERIOD-TUBERIZATION}

In photoperiod-sensitive plants, changes in daylength and temperature initiate striking alterations in growth and development. Tuberization in cultivated potato is strongly influenced by photoperiod (Ewing and Struik, 1992) because short days (SD) are required to initiate a series of adaptive and communicative events that result in tuber formation (Rodríguez-Falcón et al., 2006). So strong is the requirement for SD (long nights, more precisely) that a 5-min interruption of the dark period with red light inhibits tuberization (Batutis and Ewing, 1982), indicating involvement of phytochrome (Jackson et al., 1996). The tuberization signal is grafttransmissible from the scion to the rootstock and not vice versa (Chapman, 1958; Kumar and Wareing, 1973), but the signal identity remains unknown. Some work suggests a link between the tuberization signal and the floral induction signal, because grafting tobacco scions induced to flower onto potato stocks initiated tuberization (Chailakhyan et al., 1981). This is further supported by evidence that overexpression of the Arabidopsis gene involved in daylength control, CONSTANS, delayed tuber induction under SD conditions (Martínez-García et al., 2002a). The CONSTANS gene mediates its effect on flowering through the gene, FLOWERING LOCUS T, which is a candidate for the tuberization signal (Rodríguez-Falcón et al., 2006).

Certain gibberellins (GAs) have been shown to inhibit tuber formation and may mediate the photoperiod- and temperaturedependent tuberization responses (reviewed in Jackson, 1999 and Prat, 2004). No other PGR has been unequivocally shown to participate in communicating SD from shoot to root during tuber induction. The inactive precursor $\mathrm{GA}_{20}$ is thought to be the readily transported form of GA, whereas $\mathrm{GA}_{1}$, an active end product produced by oxidation of $\mathrm{GA}_{20}$, has limited mobility but actively inhibits tuberization (Xu et al., 1998). Under noninducing long day conditions, $\mathrm{GA}_{20}$ is not metabolized to $\mathrm{GA}_{1}$ in the leaves but is transported to the stolon, where it is converted to $\mathrm{GA}_{1}$ and inhibits tuber formation. Under SD conditions, conversion of $\mathrm{GA}_{20}$ to $\mathrm{GA}_{1}$ increases in the leaves and as a result, less $\mathrm{GA}_{20}$ is available for basipetal transport 
and conversion to active $\mathrm{GA}_{1}$ in the stolon. As a result, the levels of inhibitory $\mathrm{GA}_{1}$ in the stolon are reduced and tuber formation is initiated (Prat, 2004). Interestingly, $\mathrm{GA}_{1}$ concentration first declines precipitously at the stolon apex, which is the location of initial tuber formation (Xu et al., 1998). As tubers grow, long-term morphological changes occur throughout the plant. Changes include reduction in stem growth, increased leaf size, suppression of axillary bud outgrowth, abortion of flower buds, and hastening of senescence (Fig. 3). Crosstalk among GA, auxin, and cytokinin is thought to play a role in morphological adaptation of the
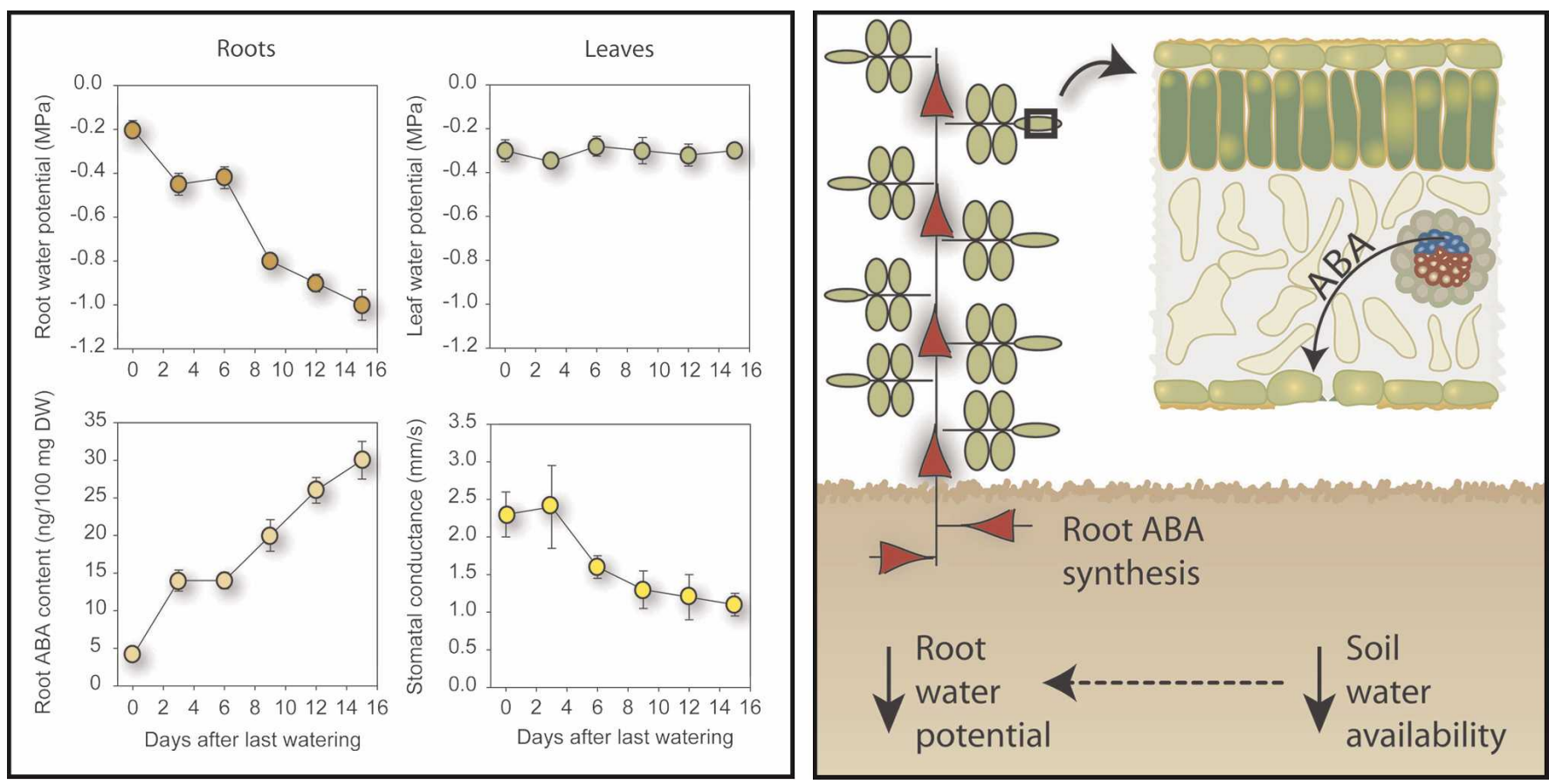

Fig. 2. Root and leaf water potential, root ABA content, and leaf $g_{\mathrm{S}}$ in corn when subjected to increased duration of soil drying (left panel). Data are from Zhang and Davies (1989). (Right panel) Diagram of a stylized tomato plant under stress after a short period of soil drying. Red arrowheads indicate ABA movement from the site of synthesis in the root and acropetal transport to leaves. Cross-section of an affected leaf (inset right panel) shows movement of ABA from xylem elements to the guard cell.
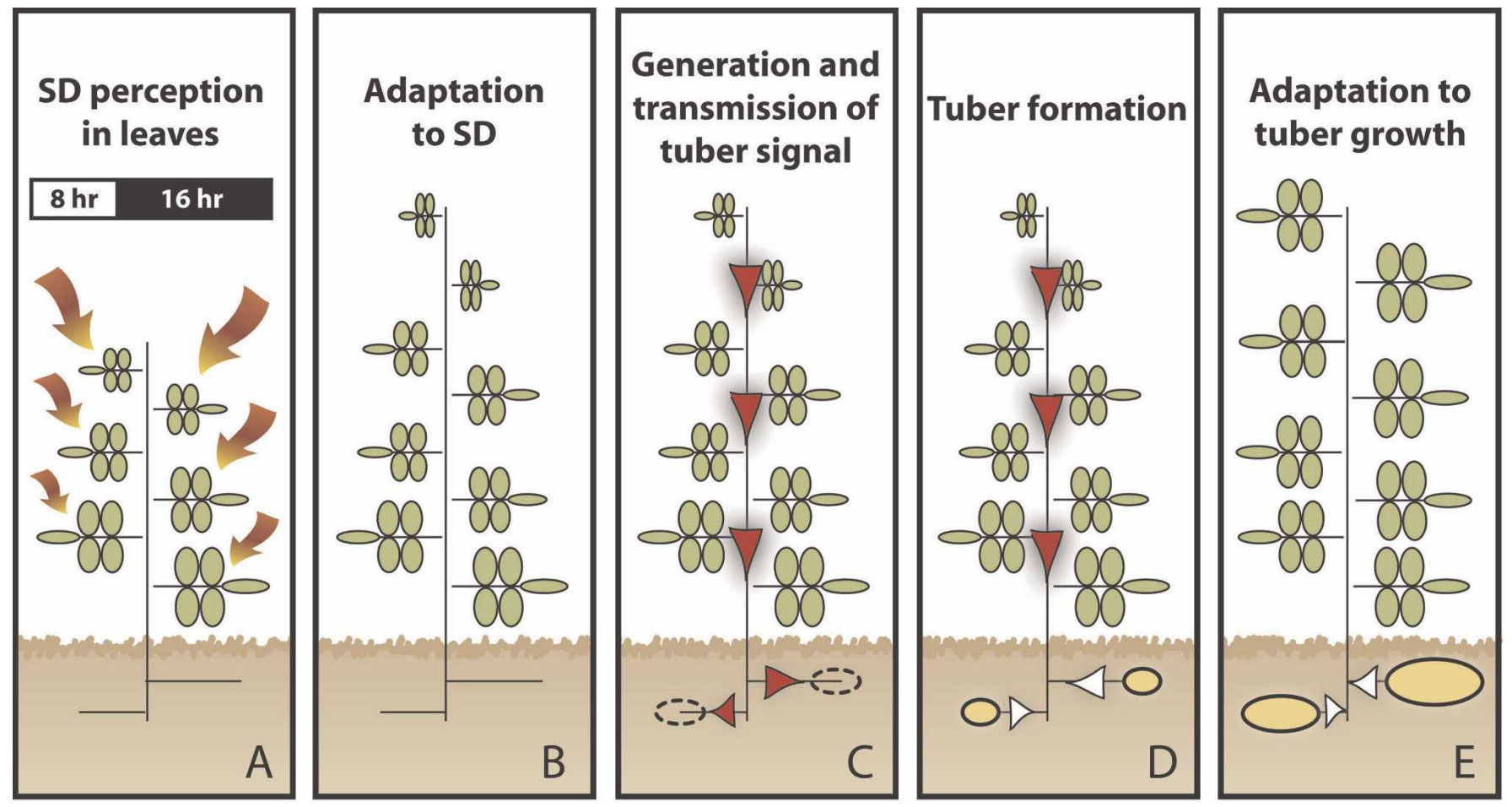

Fig. 3. Tuberization in potato. (A) Short days (SD) are perceived in the leaves; (B) increased stem elongation and reduced leaflet length associated with increased and decreased gibberellin (GA), respectively, occur as plants adapt to SD; (C) A tuberization signal with unknown identity and GA are basipetally transported to the roots, where GA promotes stolon growth but arrests tuber initiation; (D) GA decreased in stolon apices and tuber formation initiated; (E) plant adapts to tuber growth as leaves become larger, growth is inhibited, GA content is reduced, and senescence is hastened. Horizontal bar indicates hours of light and dark. Red arrowheads depict basipetal transport and movement of the tuberization signal. White arrowheads depict proximal movement of GA in stolons. Figure redrawn from Martínez-García et al. (2002b). 


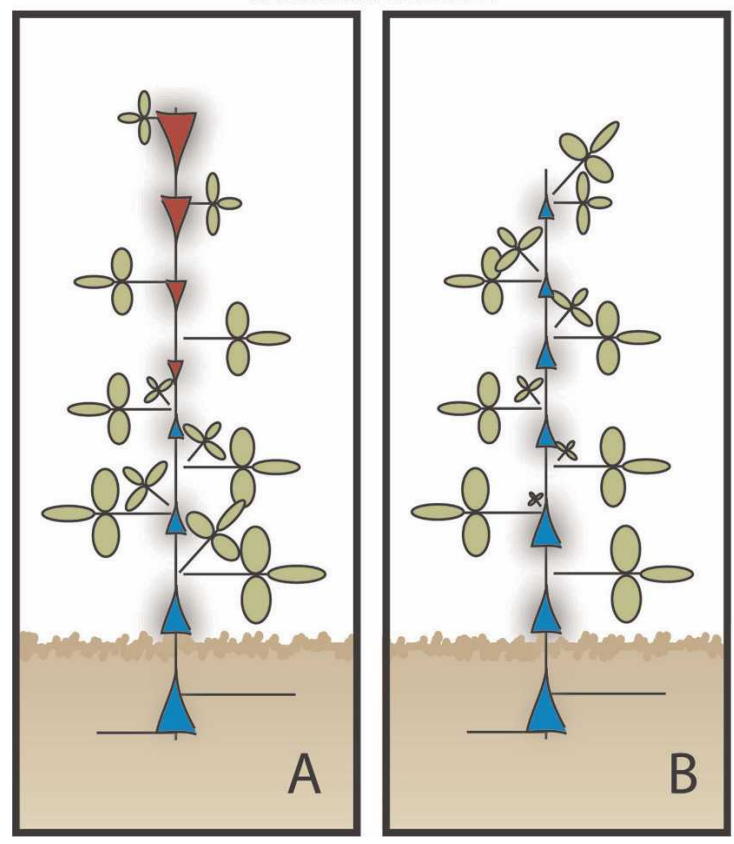

Fig. 4. Classical (A and $\mathbf{B}$ ) and shoot multiplication signal (SMS) (C and D) models of apical dominance. In the classical model, the apical meristem provides a source of basipetally moving auxin that inhibits lateral bud outgrowth, whereas root-synthesized cytokinin travels acropetally, enters the lateral bud, and initiates outgrowth. (A) Lateral buds break at locations predominantly influenced by cytokinin but not auxin. (B) Decapitation removes auxin source, increases acropetal cytokinin movement, and initiates lateral budbreak first at locations where auxin source was removed. (C) In the SMS model, auxin synthesized in the apical meristem controls axillary bud outgrowth through upregulation of root SMS. (D) If the auxin source is removed, acropetal SMS transport declines, preparing the axillary bud for outgrowth. Lowered auxin content increases cytokinin synthesized in shoot nodes adjacent to axillary buds and promotes bud outgrowth.

shoot to tuber growth (Martínez-García et al., 2002b).

\section{COMMUNICATING APICAL DOMINANCE-AXILLARY BUD OUTGROWTH}

The shoot apex exerts a central coordinating influence on plant growth and development. In the classic physiological model of apical dominance, the apical meristem contained within the shoot apex provides a source of basipetally moving auxin that inhibits lateral bud outgrowth, whereas rootsynthesized cytokinin travels acropetally in the transpiration stream, enters the lateral bud, and initiates outgrowth (Bangerth, 1994). As long as the dominant apical meristem remains intact, auxin will be transported down the stem through basally localized efflux carriers in xylem parenchyma. The lowest buds on the stem are most likely to activate in the presence of an intact apex as a result of the lower amount of auxin present and rate of degradation (Leyser, 2005; Morris et al., 2005). Auxin is known to inhibit cytokinin biosynthesis (Nordström et al., 2004). At lower auxin levels, more cytokinin would be available to initiate budbreak at lower stem locations (McSteen and Leyser, 2005). In contrast, removal of the apical bud causes a rapid reduction in auxin from the top of the stem downward, causing lateral budbreak in that order (Leyser, 2005).

The role of root-derived cytokinin as auxin's exclusive partner in communicating loss of apical dominance to axillary buds has been questioned. A novel acropetally trans- ported branching factor called shoot multiplication signal (SMS; Johnson et al., 2006) was identified in highly branched mutants of English pea (Beveridge, 2000) and petunia (Snowden et al., 2005). SMS was graft-transmissible and shown to act as a shoot-branching inhibitor regulated by auxin (Foo et al., 2005). Although not fully characterized, the gene product of a carotenoid cleavage dioxygenase could serve as the SMS or its regulator (Snowden et al., 2005). Based on this evidence, a new model of apical dominance states that auxin synthesized in intact shoot apices controls axillary bud outgrowth through the upregulation of root SMS. If the auxin source is removed, acropetal SMS transport declines, preparing the axillary bud for outgrowth. Lowered auxin content also increases cytokinin synthesized in shoot nodes adjacent to axillary buds and promotes bud outgrowth (Fig. 4; Nordström et al., 2004; Tanaka et al., 2006). Thus, auxin appears to be a primary signal communicating apical dominance, but root-derived SMS, cytokinins, and possibly other PGRs interact with auxin to initiate and sustain axillary bud outgrowth (Dun et al., 2006).

\section{CONCLUSIONS}

Communication between roots and shoots involves the interplay between different PGRs and other communicators in regulating physiological responses. Interaction between auxin and root-derived cytokinins and SMS has been identified as important for regulation of apical dominance. Similar interaction between auxin and cytokinins has been implicated in rootstock-dependent dwarfing and loss of apical dominance in apple and other horticultural crops (Bangerth et al., 2000). Although root-derived signal regulation of ABA has been suggested as being important in controlling $g_{\mathrm{S}}$ under drought conditions, cytokinin synthesis and translocation is also inhibited by drought in crops such as grapevine (Stoll et al., 2000), and cytokinins are known to alter $g_{\mathrm{S}}$ (Bradford, 1983; Stoll et al., 2000). Future studies should be aimed at understanding such interplay between different PGRs in facilitating long-distance signaling. A combination of approaches involving inhibitor applications and analysis of mutants altered in PGR synthesis or transport may shed more light on interesting facets of long-distance communication in horticultural crops.

\section{Literature Cited}

Abeles, F., P. Morgan, and M. Saltveit. 1992. Ethylene in plant biology. 2nd ed. Academic Press, San Diego, CA.

Bangerth, F. 1994. Response of cytokinin concentration in the xylem exudate of bean (Phaseolus vulgaris L.) plants to decapitation and auxin treatment, and relationship to apical dominance. Planta 194:439-442.

Bangerth, F., C.J. Li, and J. Gruber. 2000. Mutual interaction of auxin and cytokinins in regulating correlative dominance. Plant Growth Regulat. 32:205-217.

Bates, L.M. and A.E. Hall. 1981. Stomatal closure with soil water depletion not associated with changes in bulk leaf water status. Oecologia 50:62-65.

Batutis, E.J. and E.E. Ewing. 1982. Far-red reversal of red light effect during long-night induction 
of potato (Solanum tuberosum L.) tuberization. Plant Physiol. 69:672-674.

Beveridge, C.A. 2000. Long-distance signaling and a mutational analysis of branching in pea. Plant Growth Regulat. 32:193-203.

Blatt, M.R. and A. Grabov. 1997. Signaling gates in abscisic acid-mediate control of guard cell ion channels. Physiol. Plant. 100:481-490.

Bradford, K.J. 1983. Involvement of plant growth substances in the alteration of leaf gas exchange of flooded tomato plants. Plant Physiol. 73:480-483.

Bradford, K.J. and D.R. Dilley. 1978. Effects of root anaerobiosis on ethylene production, epinasty, and growth of tomato plants. Plant Physiol. 61:506-509.

Bradford, K.J. and S.F. Yang. 1980. Xylem transport of 1-aminocyclopropane -1-carboxylic acid, and ethylene precursor, in waterlogged tomato plants. Plant Physiol. 65:322-326.

Chailakhyan, M.K.H., L.I. Yanina, A.G. Davedzhiyan, and G.N. Lotova. 1981. Photoperiodism and tuber formation in grafting of tobacco onto potato. Dokl. Akad. Nauk SSSR 257:12761280.

Chapman, H.W. 1958. Tuberization in the potato plant. Plant Physiol. 11:215-224.

Davies, W.J. and J. Zhang. 1991. Root signals and the regulation of growth and development of plants in drying soil. Ann. Rev. Plant Physiol. Plant Mol. Biol. 42:55-76.

Dodd, I.C. 2005. Root-to-shoot signalling: Assessing the roles of 'up' in the up and down world of long-distance signalling in planta. Plant Soil 274:251-270.

Dun, E.A., B.J. Ferguson, and C.A. Beveridge. 2006. Apical dominance and shoot branching. Divergent opinions or divergent mechanisms? Plant Physiol. 142:812-819.

Else, M.A., K.C. Hall, G.M. Arnold, W.J. Davies, and M.B. Jackson. 1995. Export of ABA, ACC, phosphate, and nitrate from roots to shoots of flooded plants. Accounting for the effects of xylem sap flow rate on concentration and delivery. Plant Physiol. 107:377-384.

Ewing, E.E. and P.C. Struik. 1992. Tuber formation in potato. Hort. Rev. (Amer. Soc. Hort. Sci.) 14:89-198.

Fambrini, M., P. Vernieri, M.L. Toncelli, V.D. Rossi, and C. Pugliesi. 1995. Characterization of a wilty sunflower (Helianthus annuus L.) mutant. III. Phenotypic interaction in reciprocal grafts from wilty mutant and wild-type plants. J. Expt. Bot. 46:525-530.

Foo, E., E. Bullier, M. Goussot, F. Foucher, C. Rameau, and C.A. Beveridge. 2005. The branching gene RAMOSUS1 mediates interactions among two novel signals and auxin in pea. Plant Cell 17:464-474.

Forde, B.G. 2002. The role of long-distance signaling in plant responses to nitrate and other nutrients. J. Expt. Bot. 53:39-43.

Furkova, N.S. 1944. Growth reactions in plants under excessive watering. Dokl. Proc. Acad. Sci. U.S.S.R. 42:87-90.

Gowing, D.J., W.J. Davies, and H.G. Jones. 1990. A positive root-sourced signal as an indicator of soil drying in apple, Malus $\times$ domestica Borkh. J. Expt. Bot. 41:1535-1540.

Holbrook, N.M., V.R. Shashidhar, R.A. James, and R. Munns. 2002. Stomatal control in tomato with ABA-deficient roots: Response of grafted plants to soil drying. J. Expt. Bot. 53:15031514.

Jackson, M.B. 2002. Long distance signaling from roots to shoots assesses: The flooding story. J. Expt. Bot. 53:175-181.
Jackson, M.B. and J.D. Campbell. 1976. Waterlogging and petiole epinasty in tomato: The role do ethylene and low oxygen. New Phytol. 76:21-29.

Jackson, M.B., K. Gales, and D.J. Campbell. 1978. Effect of waterlogged soil conditions on the production of ethylene and on water relationships in tomato plants. J. Expt. Bot. 29:183-193.

Jackson, S., A. Heyer, J. Dietze, and S. Prat. 1996. Phytochrome B mediates the photoperiodic control of tuber formation in potato. Plant J. 9:159-166.

Jackson, S.D. 1999. Multiple signaling pathways control tuber induction in potato. Plant Physiol. 119:1-8.

Jackson, W.T. 1956. Relative importance of factors causing injury to shoots of flooded tomato plants. Amer. J. Bot. 43:637-639.

Johnson, X., T. Brcich, E.A. Dun, M. Goussot, K. Haurogne, C.A. Beveridge, and C. Rameau. 2006. Branching genes are conserved across species. Genes controlling a novel signal in pea are coregulated by other long-distance signals. Plant Physiol. 142:1014-1026.

Kawase, M. 1974. Role of ethylene in induction of flooding damage in sunflower. Physiol. Plant. 31:29-38.

Kumar, D. and P.F. Wareing. 1973. Studies of tuberization in Solanum andigena. I. Evidence for the existence and movement of a specific tuberization stimulus. New Phytol. 72:283287.

Leyser, O. 2005. The rise and fall of apical dominance. Curr. Opin. Genet. Dev. 15:468-471.

Loveys, B.R. 1984. Diurnal changes in water relations and abscisic acid in field-grown Vitis vinifera cultivars. III. The influence of xylemderived abscisic acid on leaf gas exchange. New Phytol. 98:563-573.

Martínez-García, J.F., A. Virgos-Soler, and S. Prat. 2002a. Control of photoperiod regulated tuberization in potato by the flowering time gene CONSTANS. Proc. Natl. Acad. Sci. USA 99: 15211-15216.

Martínez-García, J.F., J.L. García-Martínez, J. Bou, and S. Prat. 2002b. The interaction of gibberellins and photoperiod in the control of potato tuberization. J. Plant Growth Regulat. 20:377-386.

McSteen, P. and O. Leyser. 2005. Shoot branching. Annu. Rev. Plant Biol. 56:353-374.

Morris, S.E., M.C.H. Cox, J.J. Ross, S. Krisantini, and C.A. Beveridge. 2005. Auxin dynamics after decapitation are not correlated with the initial growth of axillary buds. Plant Physiol. 138:1665-1672.

Neuman, D.S., S.B. Rood, and B.A. Smit. 1990. Does cytokinin transport from root-to-shoot in the xylem sap regulate leaf responses to root hypoxia? J. Expt. Bot. 41:1325-1333.

Nordström, A., P. Tarkowski, D. Tarkowska, R. Norbaek, C. Åstot, K. Dolezal, and G. Sandberg. 2004. Auxin regulation of cytokinin biosynthesis in Arabidopsis thaliana: A factor of potential importance for auxin-cytokinin-regulated development. Proc. Natl. Acad. Sci. USA 101:8036-8044.

Olson, D.C., J.H. Oetkier, and S.F. Yang. 1995. Analysis of $L E-A C S 3$, a 1-aminocyclopropane1 -carboxylic acid synthase gene expressed during flooding in the roots of tomato plants. J. Biol. Chem. 270:14056-14061.

Passioura, J.B. 1988. Root signals control leaf expansion in wheat seedlings growing in drying soil. Aust. J. Plant Physiol. 15:687-693.

Prat, S. 2004. Hormonal control of tuberization. In: Davies, P.J. (ed.). Plant hormones. Biosynthesis, signal transduction, action! 3rd ed. Kluwer Academic Publishers, Dordrecht, The Netherlands.

Rodríguez-Falcón, M., J. Bou, and S. Prat. 2006. Seasonal control of tuberization in potato: Conserved elements with the flowering response. Ann. Rev. Plant Biol. 57:151-180.

Sauter, A., W.J. Davies, and W. Hartung. 2001. The long-distance abscisic acid signal in the droughted plant: The fate of the hormone on its way from root to shoot. J. Expt. Bot. 52:19911997.

Sharp, R.E. and M.E. Le Noble. 2002. ABA, ethylene and the control of shoot and root growth under water stress. J. Expt. Bot. 53: 33-37.

Snowden, K.C., A.J. Simkin, B.J. Janssen, K.R. Templeton, H.M. Loucas, J.L. Simons, S. Karunairetnam, A.P. Gleave, D.G. Clark, and H.J. Klee. 2005. The decreased apical dominance 1/Petunia hydrida CAROTENOID CLEAVAGE DIOXYGENASE 8 gene affects branch production and plays a role in leaf senescence, root growth and flower development. Plant Cell 17:746-759.

Sobeih, W.Y., I.C. Dodd, M.A. Bacon, D. Grierson, and W.J. Davies. 2004. Long-distance signals regulating stomatal conductance and leaf growth in tomato (Lycopersicon esculentum) plants subjected to partial root-zone drying. J. Expt. Bot. 55:2353-5363.

Stoll, M., B. Loveys, and P. Dry. 2000. Hormonal changes induced by partial rootzone drying of irrigated grapevine. J. Expt. Bot. 51:16271634.

Tanaka, M., T. Kentaro, M. Kojima, H. Sakakibara, and H. Mori. 2006. Auxin controls local sytokinin biosynthesis in the nodal stem in apical dominance. Plant J. 45:1028-1036.

Tardieu, F., T. Lafarge, and T. Simonneau. 1996. Stomatal control by fed or endogenous xylem ABA in sunflower: Interpretation of correlations between leaf water potential and stomatal conductance in anisohydric species. Plant Cell Environ. 19:75-84.

Trejo, C.L., A.L. Clephan, and W.J. Davies. 1995. How do stomata read abscissic acid signals? Plant Physiol. 109:803-811.

Ursin, V.M. and K.J. Bradford. 1989. Auxin and ethylene regulation of petiole epinasty in two developmental mutants of tomato, diageotropica and epinastic. Plant Physiol. 90:13411346.

Vriezen, W.H., R. Hulzink, C. Mariani, and L.A.C.J. Voesenek. 1999. 1-Aminocyclopropane-1-Carboxylate Oxidase activity limits ethylene biosynthesis in Rumex palustris during submergence. Plant Physiol. 121:189-196.

Wang, K.L.C., H. Li, and J.R. Ecker. 2002. Ethylene biosynthesis and signaling networks. Plant Cell 14:131-151.

Wilkinson, S. and W.J. Davies. 2002. ABA-based chemical signaling: The co-ordination of responses to stress in plants. Plant Cell Environ. 25:195-210.

$\mathrm{Xu}, \mathrm{X}$., A.A.M. van Lammeren, E. Vermeer, and D. Vreugdenhil. 1998. The role of gibberellin, abscisic acid, and sucrose in the regulation of potato tuber formation in vitro. Plant Physiol. 117:575-584.

Zhang, J. and W.J. Davies. 1987. Increased synthesis of ABA in partially dehydrated root tips and $\mathrm{ABA}$ transport from roots to leaves. J. Expt. Bot. 38:2015-2023.

Zhang, J. and W.J. Davies. 1989. Abscisic acid produced in dehydrating roots may enable the plant to measure the water status of the soil. Plant Cell Environ. 12:73-81. 